\title{
Cattle farmer psychosocial profiles and their association with control strategies for bovine viral diarrhea
}

\author{
N. S. Prosser, ${ }^{1 *} \odot$ M. J. Green, ${ }^{1} \odot$ E. Ferguson, ${ }^{2} \odot$ M. J. Tildesley, ${ }^{3,4} \odot$ E. M. Hill, ${ }^{3,4} \odot$ M. J. Keeling, ${ }^{3,4} \odot$ \\ and J. Kaler ${ }^{1}$ (i) \\ ${ }^{1}$ School of Veterinary Medicine and Science, University of Nottingham, Sutton Bonington Campus, Leicestershire, LE12 5RD, United Kingdom \\ ${ }^{2}$ School of Psychology, University Park, University of Nottingham, Nottingham, NG7 2RD, United Kingdom \\ ${ }^{3}$ Zeeman Institute for Systems Biology \& Infectious Disease Epidemiology Research, School of Life Sciences and Mathematics Institute, \\ University of Warwick, Coventry, CV4 7AL, United Kingdom \\ ${ }^{4}$ Joint UNIversities Pandemic and Epidemiological Research (JUNIPER; https://maths.org/juniper/)
}

\section{ABSTRACT}

Bovine viral diarrhea (BVD) is endemic in the United Kingdom and causes major economic losses. Control is largely voluntary for individual farmers and is likely to be influenced by psychosocial factors, such as altruism, trust, and psychological proximity (feeling close) to relevant "others," such as farmers, veterinarians, the government, and their cows. These psychosocial factors (factors with both psychological and social aspects) are important determinants of how people make decisions related to their own health, many of which have not been studied in the context of infectious disease control by farmers. Farmer psychosocial profiles were investigated using multiple validated measures in an observational survey of 475 UK cattle farmers using the capability, opportunity, motivation-behavior (COMB) framework. Farmers were clustered by their BVD control practices using latent class analysis. Farmers were split into 5 BVD control behavior classes, which were tested for associations with the psychosocial and COM-B factors using multinomial logistic regression, with doing nothing as the baseline class. Farmers who were controlling disease both for themselves and others were more likely to do something to control BVD (e.g., test, vaccinate). Farmers who did not trust other farmers, had high psychological capability (knowledge and understanding of how to control disease), and had high physical opportunity (time and money to control disease) were more likely to have a closed, separate herd and test. Farmers who did not trust other farmers were also more likely to undertake many prevention strategies with an open herd. Farmers with high automatic motivation (habits and emotions) and reflective

Received October 6, 2021.

Accepted December 5, 2021.

*Corresponding author: Naomi.Prosser@nottingham.ac.uk motivation (decisions and goals) were more likely to vaccinate and test, alone or in combination with other controls. Farmers with high psychological proximity (feeling of closeness) to their veterinarian were more likely to undertake many prevention strategies in an open herd. Farmers with high psychological proximity to dairy farmers and low psychological proximity to beef farmers were more likely to keep their herd closed and separate and test or vaccinate and test. Farmers who had a lot of trust in other farmers and invested in them, rather than keeping everything for themselves, were more likely to be careful introducing new stock and test. In conclusion, farmer psychosocial factors were associated with strategies for BVD control in UK cattle farmers. Psychological proximity to veterinarians was a novel factor associated with proactive BVD control and was more important than the more extensively investigated trust. These findings highlight the importance of a close veterinarian-farmer relationship and are important for promoting effective BVD control by farmers, which has implications for successful nationwide BVD control and eradication schemes.

Key words: bovine viral diarrhea, COM-B, farmer behavior, psychological proximity, psychosocial profiling

\section{INTRODUCTION}

Bovine viral diarrhea (BVD) is endemic in the United Kingdom and causes major economic losses that result from poor growth rates and pneumonia, reduced milk production, reduced fertility, fatalities from mucosal disease, and increased susceptibility to other diseases (Houe, 1999; Weldegebriel et al., 2009). Bovine viral diarrhea transmission occurs primarily through persistently infected (PI) cattle, which are created when the dam becomes infected early in pregnancy (McClurkin et al., 1984). These calves are immunotolerant to the BVD virus (Peterhans et al., 2003) and shed virus their entire life. Other cattle are transiently infected and act 
as a weaker source of infection, being infectious for a much shorter period.

There are many strategies farmers can adopt to control BVD, ranging from measures to prevent the introduction and transmission of infectious diseases in general to the BVD specific measures of testing, culling PI cattle, and vaccination. The decisions farmers make within their own herd have implications for national disease control, with frequent movements between cattle holdings and markets in the United Kingdom (Vernon, 2011) and the potential for local disease transmission between neighboring herds (Abernethy et al., 2011; Graham et al., 2016). There is a potential incentive to free-ride and rely on other people to control disease (Bauch and Earn, 2004). Where national BVD prevalence is high, maintaining freedom from disease in a herd is more costly (Gunn et al., 2005). Bovine viral diarrhea control is voluntary in England and Wales, and farmers can engage with voluntary schemes [BVDFree (BVDFree, 2021) and Gwaredu BVD (Gwaredu BVD, 2019)]. In contrast, BVD testing is mandatory in breeding herds in Scotland and Northern Ireland, with movement restrictions on PI cattle to incentivize control.

The undertaking of any given behavior is influenced by a person having sufficient capability (e.g., physical ability, knowledge, and understanding), opportunity (e.g., physical resources and support from others), and motivation (e.g., both reflective decision making and automatic habits and emotions; Michie et al., 2011, 2014). The capability, opportunity, motivationbehavior (COM-B) framework of behavior change captures these interrelated attributes, encompasses existing frameworks for behavior in health settings, and has been applied to farmer and veterinary behavior (Michie et al., 2011; Hardefeldt et al., 2018; Carroll and Groarke, 2019). The COM-B framework has traditionally been used to study predictors of individual behavior change. However, infection control, be it via vaccination or behavioral controls, requires an appreciation of the dynamic relationship with people. For example, vaccination carries a personal cost, but benefits both the person vaccinated and those not vaccinated. Thus, the nonvaccinated can pay no cost and free-ride on others' decisions to vaccinate (Bauch and Earn, 2004; Böhm et al., 2016). Therefore, to fully understand infection control decisions it is necessary to include assessment of key mechanisms underlying cooperation: generosity, altruism, trust, fairness, and proximity (Fehr and Fischbacher, 2003; Nowak, 2006; Rand and Nowak, 2013; Bradley et al., 2018; Dimick et al., 2018). These psychosocial factors (factors with both psychological and social aspects) come from a separate theoretical literature to the COM-B framework and are more intrinsic to a person's nature than the COM-B factors.

People with altruistic (defined here as seeking to benefit others at a personal cost; West et al., 2007; Bshary and Bergmüller, 2008; Pfattheicher et al., 2022) and prosocial (aim for equality) preferences tend to make health decisions that benefit others. In contrast, people with more selfish or proself (seek to benefit self) preferences make decisions that benefit themselves. For example, prosocial individuals are more likely to get vaccinated, unlike proself people who are more likely to rely on herd immunity (Böhm et al., 2016). People may also show reactive reluctant altruism, behaving in a way that benefits others but only because they do not trust others to help, which, for example, is important in blood donation behavior (Ferguson et al., 2012; Ferguson, 2022). Behaviorally, generosity and altruism can be investigated using dictator games where a decision maker chooses how to split an endowment between themselves and another person (Forsythe et al., 1994). The dictator game can be modified with different recipients and different contexts for the original endowment that is to be split (e.g., it could have been earned, a gift, or lottery winnings) to investigate how altruistic the decision maker is (Engel, 2011). Altruism can also be investigated using the social value orientation (SVO) slider measure (Murphy et al., 2011) where participants make 6 dictator game decisions from a series of set responses. Their responses are used to calculate a score of how altruistic they are which can used to categorize participants as competitive $(<-12.04$, maximizes the difference in benefit to self versus benefit to other), individualistic ( -12.04 to 22.45 , maximizes benefit to self), prosocial (22.45 to 57.15, maximizes joint gain or minimizes inequality), or altruistic ( $>57.15$, maximizes benefit to other; Murphy et al., 2011).

People are generally more likely to help those they feel close to or are psychologically proximal to (Cialdini et al., 1997). High psychological proximity is associated with increased uptake of behavior to protect other people's health (Tu et al., 2021) and increased support for others to change their behavior (Bobak and Raupach, 2018). Psychological proximity can be measured using the inclusion of other in self (IOS) scale (Aron et al., 1992), where participants select a pair of overlapping circles from a scale of increasingly overlapping circles that best represents how close they feel to a specific "other" in question. Trust that others will control infectious diseases is another important factor and promotes cooperation with prosocial disease control behavior such as BVD control schemes (Heffernan et al., 2016; Pletzer et al., 2018). Cattle farmers in the United Kingdom generally have high trust in veterinary advice and low trust in government policy. 
They are more likely to follow trusted veterinary advice than want to cooperate with government recommendations (Brennan and Christley, 2013; Fisher, 2013; Bard et al., 2019). Behaviorally, trust and trustworthiness can be investigated with investment games (also known as trust games; Berg et al., 1995). In these games the investor chooses how much of an endowment to invest in another unknown person. The amount invested is multiplied (usually tripled) and the investee chooses how much of the multiplied investment to return to the investor. Thus, increasing the amount invested indexes how trusting the investor is that the investee will act in a trustworthy manner and return a fair amount on the investment. Expectations of trust in others can be gauged by asking investors to estimate how much they believe an investee will return. Thus, the trust game also taps concepts of cooperation, and reciprocity (Ferguson et al., 2020). Modifications can also be made to this game for the particular context to be studied.

In this paper we investigate psychosocial profiles of UK cattle farmers, many of which have not been investigated in farmers to date, to evaluate how individual profiles and factors from the COM-B framework of behavior change, are associated with the farmers' strategy to control BVD in their herd.

\section{MATERIALS AND METHODS}

Ethical approval was obtained from the University of Nottingham Research Ethics Committee for both the focus groups and the survey before commencement of the study (reference number: 2789 190711, granted: June 22, 2019).

\section{Focus Group Design, Recruitment, and Analysis}

A series of focus groups $(n=4)$ was conducted to inform the development of a farmer survey of psychosocial characteristics and infectious disease control. A focus group guide was designed to investigate altruism, trust, psychological proximity, and the COM-B framework of behavior change (Michie et al., 2011) in the context of BVD control in a 1-h discussion. The facilitator used the questions and prompts in the focus guide to start the discussion and ensure that the farmers discussed all areas of interest, but otherwise allowed the farmers to talk freely. During the focus group, participants were provided with a printout of the IOS scale, a measure of psychological proximity (Aron et al., 1992; Mashek et al., 2007), as a discussion aid (Supplemental Figure S1; https://rdmc.nottingham.ac.uk/handle/internal/ 9483). The question guide was modified slightly between the first and subsequent focus groups to improve probing on other-regarding preferences (e.g., prosocial- ity, altruism). The same facilitator conducted all focus groups.

Focus groups were conducted in February 2020 in 3 geographical areas (Nottinghamshire, Somerset, and Yorkshire), with 3 to 8 farmers per group. All farmers had a minimum of 100 dairy cows, and each group contained both farmers who were part of the national BVD eradication program (BVDFree England) and those who were not. Three of the 4 focus groups also contained both farmers who had regular routine visits from their veterinarian and those who did not. Farmers were recruited as a convenience sample from herds associated with the University of Nottingham (2 focus groups) and 2 veterinary practices (2 focus groups). The focus groups took place at the Centre for Dairy Science Innovation at the University of Nottingham or at veterinary practices and were recorded and transcribed by an external agency (Penguin Transcription). Transcripts were checked once against the audio file by the author (NP). Theoretical thematic analysis (Braun and Clarke, 2006) of all transcripts was conducted to identify and explore the psychosocial constructs that should be included on the broader farmer survey.

\section{Survey Design}

A survey was designed to cover a wide spectrum of relevant other-regarding preferences. These included altruism (West et al., 2007; Bshary and Bergmüller, 2008; Pfattheicher et al., 2022), reactive reluctant altruism (helping because of lack of trust that others will help; Ferguson et al., 2012; Ferguson, 2022), and trust and distrust (McKnight and Chervany, 2001). Altruism was assessed using the SVO slider measure questions in which farmers chose to allocate money between themselves and another unknown farmer (Murphy et al., 2011). This task was incentivized; 10 farmers were selected at random to receive a financial reward for one of their decisions, paid to themselves and another random survey respondent; payment based on one decision is commonly used for this type of economic decision and has the advantage of reducing hedging (Charness et al., 2016). Altruism was also investigated using a dictator game where farmers could share $£ 700$ (\$877.80) hypothetical lottery money between themselves, an unknown farmer, a known farmer, an unknown veterinarian, a known veterinarian, and a stranger. Hypothetical pay does not alter dictator game decisions (Engel, 2011). Trust was investigated using an investment game (Berg et al., 1995) where $£ 50$ hypothetical lottery winnings could be invested in another unknown farmer. Investments were tripled and the farmers were asked how much they would expect the other farmer to return. Altruism, reluctant altruism, trust, and distrust were also 
investigated by Likert-scale questions created by the authors investigating trust and distrust in farmers, veterinarians, government, strangers, the National Farmers' Union, and the farming press (section 4, question 4 in Supplemental File S1; https://rdmc.nottingham.ac .uk/handle/internal/9483).

We assessed factors associated with other-regarding preferences such as psychological proximity (Aron et al., 1992; Mashek et al., 2007), general motivation for behavior using the COM-B framework (Michie et al., 2014), and anxiety about BVD. Psychological proximity with farmers, veterinarians, the government, the National Farmers' Union, and their cows was investigated using the IOS scale (Aron et al., 1992; Mashek et al., 2007). Each set of increasingly overlapping circles was given a score of 1 to 7 , with higher numbers for increased overlap which represented increased psychological proximity (Supplemental Figure S1). The COM-B questions were based on a published question guide (Michie et al., 2014), with additional relevant questions from other published uses of the guide (Barker et al., 2016; Taylor et al., 2016; Bobak and Raupach, 2018). The COM-B questions were used to explore psychological capability (knowledge and understanding), physical opportunity (time and money), social opportunity (support from others), automatic motivation (habits and emotions), and reflective motivation (plans and goals). Physical capability (ability) was not considered relevant so was not investigated in the survey. We considered that a lack of physical capability would preclude farmers from keeping cattle; therefore, it was not applicable to this group of people. Anxiety about BVD was assessed on a 5 -point scale of how anxious farmers felt about a BVD breakdown on their farm. Farmers were also asked questions to gather demographic information and to capture their current implementation of BVD control strategies.

The survey was tested by members of the research group and in a pilot study conducted using a convenience sample of 8 cattle farmers. The final survey in full is provided in Supplemental File S1.

\section{Survey Dissemination}

The survey was open from July 13 to October 5, 2020. The survey link was emailed to 10,560 British dairy and English beef levy payers by the Agriculture and Horticulture Development Board, and various cattle interest organizations also promoted the survey via magazine articles, e-newsletters, social media posts, website posts, and emails to UK cattle farmers. A hardcopy was also posted to a random sample of 2,000 of the dairy and 2,000 of the beef levy payers. The ran- dom selection for the farmers who were rewarded with a payment based on their SVO decisions was conducted in R statistical software (v3.6.2; R Core Team, 2019).

\section{Data Entry and Analysis}

Data entry for the postal surveys was conducted by an outside agency (Wyman Dillon Ltd.), except for the final 8 late returns which were conducted by the author (NP). All data analysis was conducted using $\mathrm{R}$ statistical software (v3.6.2; R Core Team, 2019) and each analysis used only the complete responses for the relevant survey questions.

\section{Factor Analyses}

To identify latent groupings and reduce the number of variables for analysis, factor analysis (Thurstone, 1947) was conducted on 32 Likert-scale items regarding reluctant altruism, altruistic or proself preferences, trust, and distrust. The factor analysis was conducted using the psych package (v2.0.8) with maximum likelihood and oblimin rotation (Revelle, 2020). Likert-scale questions were converted to numeric (1-5 for ascending strength of agreement). The number of factors was chosen based on parallel analysis, fit statistics (Tucker-Lewis index $\geq 0.9$ and root mean squared error of approximation $\leq 0.06 ; \mathrm{Hu}$ and Bentler, 1999), and a minimum of 2 variables loaded to each factor. Loadings $\geq 0.3$ were considered to define a factor. Items that were cross-loaded on 2 factors were retained in the model if their omission did not change the model fit. Factor scores for each respondent were calculated from every statement in the factor analysis, weighted by its loading (regardless of size of loading). Cronbach's $\alpha$ was calculated for each factor to assess internal reliability. If Cronbach's $\alpha$ was $<0.7$ and could be improved with omission of an item, the item was omitted.

The COM-B items were grouped by their overarching factor (psychological capability, physical opportunity, social opportunity, automatic motivation, and reflective motivation). The Likert-scale responses were also converted to a numeric response (1-5 for ascending strength of agreement). Factor scores were created by taking the mean score of the items in that factor, with an item's scale inverted if necessary (Supplemental Table S1; https://rdmc.nottingham.ac.uk/handle/ internal/9483).

\section{Latent Class Analysis}

Two latent class analyses were conducted to identify clusters of farmers from their responses: 
(1) Three items from the economic games were rescaled to proportions for comparative purposes: the proportion of $£ 50$ that each farmer invested, the proportion of tripled investment each farmer expected to be returned in the investment game, and the proportion of $£ 700$ each farmer gave away in the dictator game.

(2) The BVD control behaviors of the farmers: buy only from BVD-free herds, closed herd, disinfection for people entering the farm, separation from neighboring stock, isolate or test new cattle, vaccinate, blood or tissue test, milk test, cull PI, and isolate sick animals.

Latent class analysis was conducted using the mclust (v5.4.6) package (Fraley and Raftery, 2002; Scrucca et al., 2016). Models were selected as the spherical or diagonal mixture model with the highest Bayesian information criterion (BIC) where at least $5 \%$ of farmers were in each class and there was good delineation of the classes (normalized entropy $>0.7$ ).

\section{Multinomial Logistic Regression}

To investigate associations between farmer BVD control behaviors and psychosocial factors, the BVD latent classes were evaluated as a multinomial outcome in a logistic regression model with explanatory covariates: economic games latent class, altruism and trust factors, psychological proximity to others, each COM-B factor (psychological capability, physical opportunity, social opportunity, automatic motivation, and reflective motivation), and anxiety about a BVD breakdown. The models were built with the nnet (v7.3.12) package (Venables and Ripley, 2002).

Each independent variable was initially tested in a univariable model and initially all significant variables $(P<0.05)$ were selected to test in a multivariable model. Terms that were not significant in the multilevel model were removed from the model and all terms were retested in the final model. Spearman rank correlations were calculated for all variables considered for inclusion in the multivariable model. Variables that were correlated $(\geq 0.3)$ with a variable in the final model were tested in the model in place of their correlated variable. Models where correlated terms were significant when substituted in the final model are presented as alternative models. Demographic data were not included in the multivariable model because these were all categorical and there were insufficient respondents to avoid small and empty contingency table cells in the model. However, each demographic variable was tested in the final model to check for confounding. The United Kingdom was split into northern (Scotland,
Northern Ireland, and English counties north of and including Cheshire, Derbyshire, Nottinghamshire, and Lincolnshire) and southern (Wales and all remaining English counties) areas to test in the model. Additionally, the southwest (Gloucestershire, Wiltshire, Dorset, and more southwesterly counties) were separated out and the variable retested in the model (north, south, southwest). Model fit was evaluated by predicting BVD behavior class from both the full and $10 \times 10$-fold cross-validated models and comparing the proportion of times the correct class was predicted, and with a Hosmer-Lemeshow goodness-of-fit test (Fagerland and Hosmer, 2012).

Conditional autoregressive models (Lee, 2013) were created to investigate potential spatial confounding of the psychosocial factors at the county level. No confounding was identified and the methods and results for these are presented in Supplemental File S2 (https:// rdmc.nottingham.ac.uk/handle/internal/9483).

\section{RESULTS}

\section{Descriptive Statistics of Survey Respondents}

A total of 291 online survey responses were received from July 16 to October 5, 2020, which was 50.4\% (/577) of started surveys. A further 184 surveys were returned by post (response rate of $4.6 \%$ ), making a total of 475 survey responses. The mean pay-out to the 20 prize-winning farmers was $£ 74.25$ (range $£ 15-£ 100$ ). Most respondents were in England (73\%), with $14 \%$ in Scotland, 7\% in Wales, and 2\% in Northern Ireland. Most farmers were in their 50s and $60 \mathrm{~s}(30 \%$ and $25 \%$, respectively), with $7 \%$ under $30,10 \%$ in their 30 s, $16 \%$ in their 40 s, and $11 \%$ over 70 . Seventy-six percent of farmers had beef cattle, with a median of 70 animals over 6 mo old (range $0-850$ ), and $39 \%$ had dairy cattle, with a median of 180 adult cows (range $2-1,309$ ).

\section{Farmer SVO and Levels of Trust and Distrust}

Most farmers were categorized by their SVO slider measure responses as prosocial $(75.4 \%), 16.6 \%$ were individualistic, and very few were altruistic $(1.3 \%)$ or competitive $(0.4 \%)$.

Veterinarians were the most trusted group, least distrusted group, and farmers also felt the most respected by them. Eighty-one percent of farmers trusted their veterinarian compared with the National Farmers' Union $(57 \%)$, dairy farmers (47\%), beef farmers (38\%), and governmental organizations (19\%). More farmers agreed that they felt respected by their veterinarian (85\%), with $67 \%$ agreeing that they felt respected by the veterinary profession, whereas $49 \%$ and $10 \%$ felt 
Table 1. The items loaded ( $>0.3$ ) onto each of the 7 factors from a factor analysis of 436 complete responses to Likert-scale items on reluctant altruism, altruistic or proself preferences, trust, and distrust in a survey of UK cattle farmers

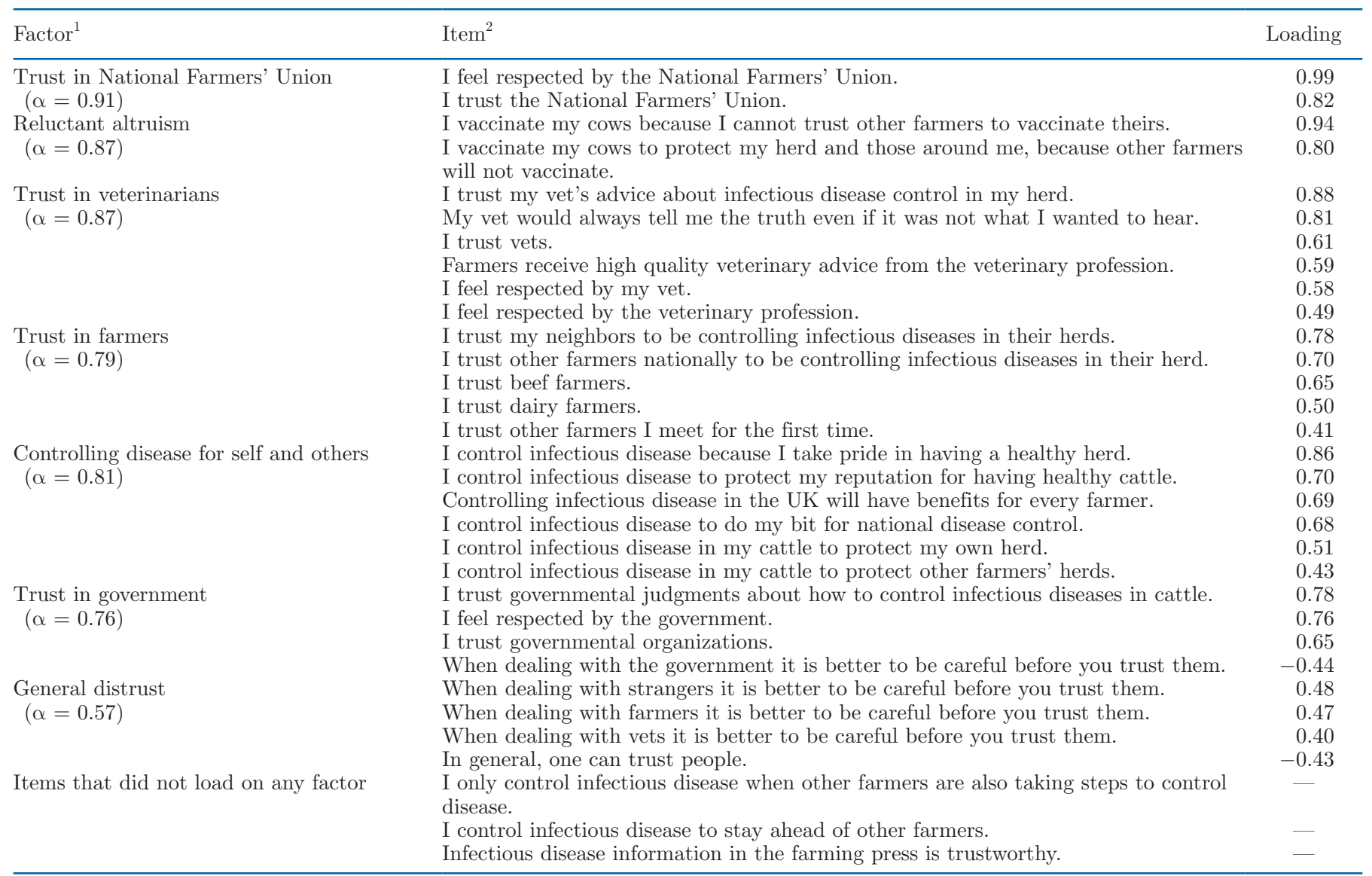

' $\alpha=$ Cronbach's $\alpha$.

${ }^{2}$ vet $=$ veterinarian

respected by the National Farmers' Union and government, respectively. Similarly, only $31 \%$ of farmers thought it was better to be careful before you trust veterinarians, rising to $56 \%$ for farmers, $63 \%$ for government, and $76 \%$ for strangers. Only $17 \%$ trusted farmers they met for the first time.

Trust in veterinarians was even higher when it was specifically for veterinary services and infectious disease control compared with general trust: $90 \%$ trusted their veterinarian's advice, $90 \%$ agreed that their veterinarian would always tell them the truth even if it was not what they wanted to hear, and $80 \%$ agreed that farmers received high-quality advice from the veterinary profession. There was less trust in other stakeholders, with $43 \%$ agreeing that infectious disease information in the farming press was trustworthy, 35\% and 30\% trusting their neighbors and other farmers nationally, respectively, to control infectious diseases, and only $16 \%$ of farmers trusting governmental judgments about disease control.
A 7-factor solution gave the best fit in a factor analysis of 436 complete responses to the other-regarding preferences, reluctant altruism, trust, and distrust Likert-scale measures (Tucker-Lewis index $=0.88$, root mean squared error of approximation $=0.06$; Table 1 ). "I trust other farmers I meet for the first time" loaded on both "trust in farmers" and "general distrust" factors ( 0.41 and -0.35 , respectively) and was retained in the model because its omission did not alter the model. Factor loadings are presented in Table 1. Cronbach's $\alpha$ was $>0.7$ for all factors except "general distrust"; however, this was not improved by omission of any of its items (Table 1).

\section{Farmer Behaviors in the Economic Games}

Seventy-four percent of farmers made an investment in the trust game. The mean proportion invested by the investors was 0.53 of $£ 50$ (range $0.02-1.00$ ) and the mean proportion of the tripled investment that the 

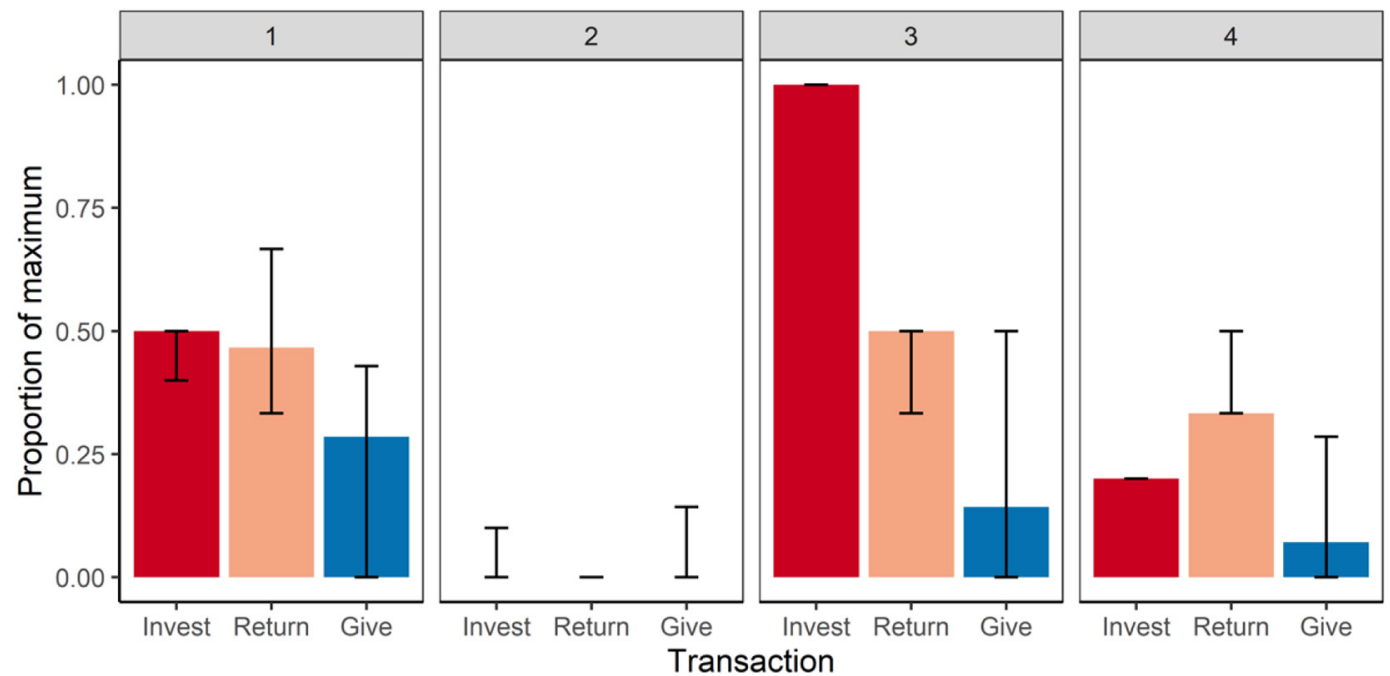

Figure 1. The median responses and interquartile range of the 4 latent classes of the behaviors of 417 farmers in the economic games. Invest $=$ proportion of $£ 50(\$ 62.70)$ invested in an unknown farmer in the investment game; return $=$ proportion of the tripled investment expected back from the unknown farmer; give $=$ proportion of $£ 700$ given away to others in the dictator game. The latent classes are as follows: $1=$ generous self-oriented mutual benefit: the most generous class that invests some and expects other farmers to be fair; $2=$ Homo economicus (selfish): keeps everything and does not trust other farmers to be fair; $3=$ mutually beneficial joint maximizer: risk taking in investing everything in unknown farmers who they trust to be fair; 4 = self-oriented mutual benefit: cautiously invests a small amount, keeping most of the possible investment from the other farmer who they do not trust to be fair as much as the other 2 investing classes.

investors expected the other farmer to return was 0.42 (range 0.00-1.00).

Forty-seven percent of farmers gave some money in the dictator game, with both the total generosity and its distribution between the recipients varying by farmer. For the farmers who gave money, the mean proportion given away was 0.39 of $£ 700$ (range $0.01-1.00$ ). The farmers were most generous to neighboring farmers with a mean gift of 0.16 of the lottery money, the local veterinarian received 0.12 , the unknown farmer 0.05 , the stranger 0.04, and the unknown veterinarian 0.02 .

Farmers split into 4 latent classes to describe their investment and generosity decisions (Figure 1), using the complete responses from 417 farmers. An ellipsoidal, equal volume, and equal shape mixture model had the best $\mathrm{BIC}(\mathrm{BIC}=412.67$, log-likelihood $=$ 296.83 , normalized entropy $=0.98)$. The 4 classes are described in detail in Supplemental File S3 (https:// rdmc.nottingham.ac.uk/handle/internal/9483). Briefly, farmers in the first and largest class, "generous selforiented mutual benefit," invested half, expected an equal split of the investment back, and were generous (35\% of farmers). This class was the most altruistic in the dictator game, but not willing to invest everything in farmers that they did not completely trust, so kept half of the possible investment. This investment game strategy means that farmers benefit overall but the investing farmer benefits the most. The second largest class, "Homo economicus (selfish)," invested nothing and kept everything (30\% of farmers); these farmers could be classed as selfish profit maximizers who do not trust other farmers to be fair. The third largest class, "mutually beneficial joint maximizer," invested everything, expected an equal split of the investment back, and gave some away (19\% of farmers). This investment strategy maximizes the number of resources available to farmers in general, and therefore farming. This class of farmer would end up with the most total resources if the investment recipient returns the proportion of investment that the farmer expects. This strategy reveals a high level of trust in other farmers and a willingness to risk investing everything in other farmers. The final and smallest class, "self-oriented mutual benefit," invested some, expected a less than equal split of the investment back, and gave very little away (16\% of farmers). This class is less altruistic than the "generous self-oriented mutual benefit" class and invested less. These farmers are cautiously investing only a small amount to farmers who they do not trust to be very fair.

\section{Farmer Psychological Proximity to Others}

The farmers felt closer to their cows (mean score of 6.0, Supplemental Figure S1) than any of the groups of people and were closer to known groups than unknown groups of people. Similar to their level of trust, the farmers felt closer to their veterinarian (4.8) than to neighboring farmers (3.9), the veterinary community 
(3.5), dairy farmers (3.4), beef farmers (3.4), the farming community (3.3), the National Farmers' Union (3.0), and the government (2.0). There was a range of scores of 1 to 7 for all groups.

\section{BVD Control Methods Used by Farmers}

Farmers split into 9 latent classes to describe their BVD control decisions using the complete responses from 467 farmers; detailed descriptions of each class are given in Table 2. A spherical, equal volume mixture model had the best BIC (BIC $=-5,269.64$, loglikelihood $=-2,330.58$, entropy $=0.89)$. Farmers were fairly evenly split across all 9 classes: "doing nothing" $(12 \%)$, "closed, separate and testing" (15\%), "vaccinating" (17\%), "vaccinating, testing and culling" (8\%), "careful introducing new stock and testing" (9\%), "careful introducing new stock, separate, and testing" (7\%), "careful introducing new stock, separate, testing, and disinfecting people" (8\%), "careful introducing new stock, separate, vaccinating, and testing" (14\%), "careful introducing new stock, separate, vaccinating, testing, and disinfecting people" (11\%).

\section{Multinomial Logistic Regression of Disease Prevention}

Latent classes that contained similar BVD management strategies were merged to reduce the number of classes in the multinomial model, resulting in 5 classes (Table 3). Briefly, these classes were (1) doing nothing, (2) closed herd, separated from neighboring stock and testing, (3) vaccinating and testing, (4) careful introducing new stock and testing, and (5) undertaking many prevention strategies with an open herd. Univariable model results examining demographic variables and psychological constructs are provided in Supplemental Tables S2 and S3 (https://rdmc.nottingham .ac.uk/handle/internal/9483), and the multivariable model results are presented in Table 4 .

In the multivariable model of 380 farmers, farmers who "controlled disease for themselves and others" were more likely to be in any class for BVD control than doing nothing. Farmers who did not trust other farmers, had high psychological capability, and had high physical opportunity were more likely to have a closed, separate herd and be testing than doing nothing. Farmers who did not trust other farmers were also more likely to be undertaking many prevention strategies with an open herd. Farmers with high automatic and reflective motivation were more likely to be in the classes that were vaccinating and testing, alone or in combination with other controls. Farmers with high psychological proximity to their veterinarian were more likely to be undertaking many prevention strategies in an open herd. Farmers with high psychological proximity to dairy farmers and low psychological proximity to beef farmers were more likely to keep their herd closed and separate and test or vaccinate and test than do nothing. Finally, farmers who were in the "mutually beneficial joint maximizers" latent class rather than selfish were more likely to be careful introducing new stock and testing rather than doing nothing.

There was no evidence of confounding of the demographic variables and little evidence of spatial autocorrelation (Supplemental File S2). There was no evidence of poor model fit in a Hosmer-Lemeshow goodness-of-fit test $\left(\chi^{2}=25.9, \mathrm{df}=32, P=0.768\right)$ or when evaluating cross-validated predictions.

\section{DISCUSSION}

This study aimed to investigate farmer psychosocial factors and their association with the undertaking of on-farm BVD control measures. A key strength of the study was that we used established psychosocial measures and theory to underpin our survey questions and analysis. The major findings were that psychological proximity to veterinarians, trust in farmers, automatic and reflective motivation, psychological capability, and physical opportunity were important for farmer behavior regarding BVD control strategies; these are discussed in turn below.

Psychological proximity to veterinarians is a novel psychosocial construct of importance for cattle infectious disease control. Farmers who felt close to their veterinarian were more likely to do more to prevent and control BVD in an open herd. This is a novel field of application for the IOS scale and there is only limited research into psychological proximity in human health behavior (Bobak and Raupach, 2018; Tu et al., 2021). The IOS scale correlates with both feeling close and behaving close (Aron et al., 1992), which could explain why farmers who had higher psychological proximity to their veterinarian were more likely to do more to prevent and control BVD if they had an open herd, behaviors that tend to align with veterinary advice. Trust is part of the interpretation that respondents give to the IOS scale and the two are correlated (Kong, 2018; Kleinert et al., 2020). Therefore, farmers who felt closer to their veterinarian also had greater trust in veterinarians (correlation coefficient $=0.52$ ). However, psychological proximity includes aspects other than just trust: behavioral closeness, connection with the other, independence from the other, and similarities with the other, which is also part of how respondents interpret the IOS scale (Aron et al., 1992). Trust in veterinarians is commonly found as an important factor in cattle farmer infectious 
Prosser et al.: FARMER PSYCHOSOCIAL PROFILES AND BVD CONTROL

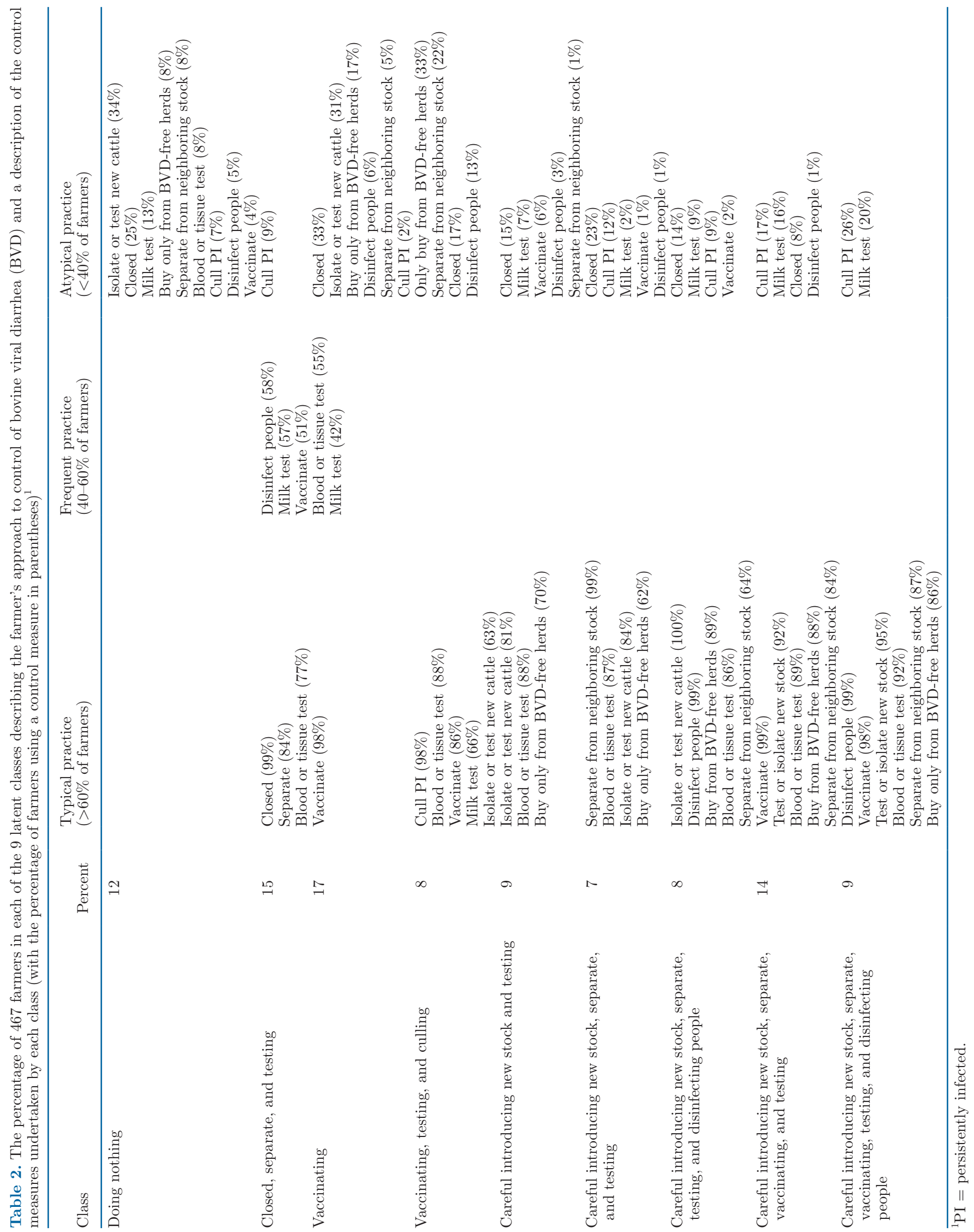


Prosser et al.: FARMER PSYCHOSOCIAL PROFILES AND BVD CONTROL

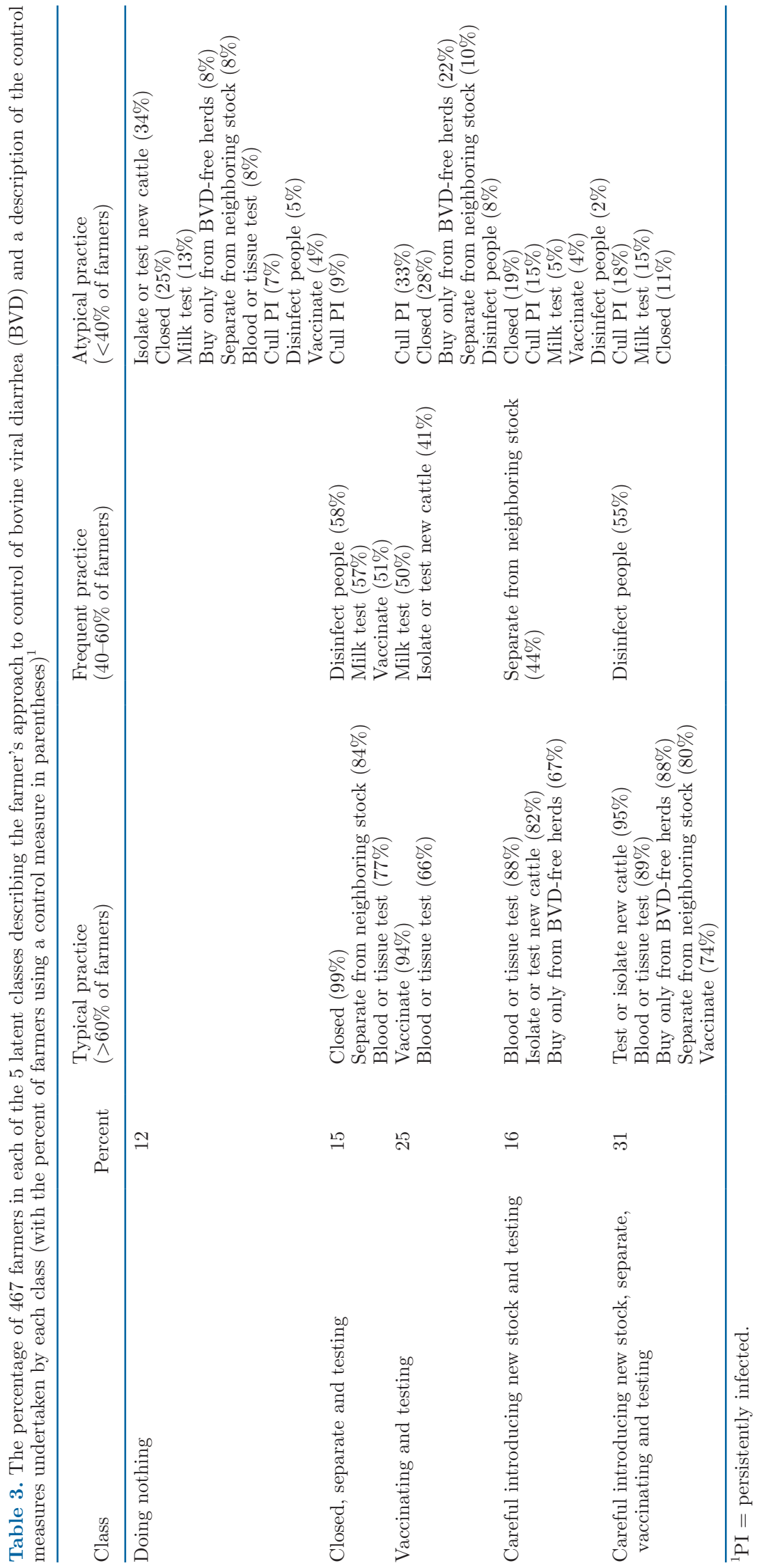


Prosser et al.: FARMER PSYCHOSOCIAL PROFILES AND BVD CONTROL

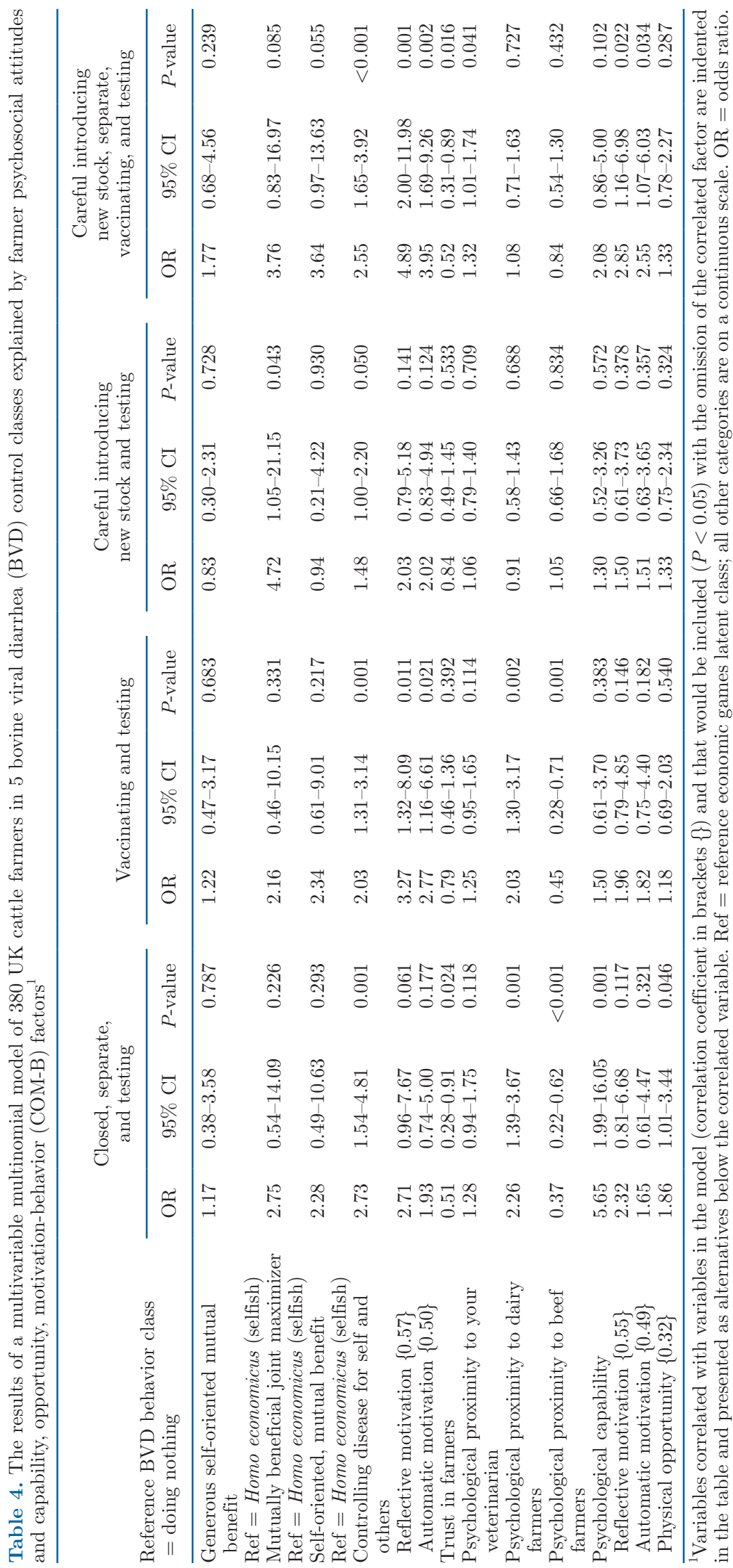


disease control behavior in the literature (e.g., Brennan and Christley, 2013; Hernández-Jover et al., 2016; Bard et al., 2019); however, here psychological proximity was more important. Veterinarians and farmers frame biosecurity in different ways, hindering the veterinarianfarmer relationship (Shortall et al., 2016). Therefore, veterinarians have a role in increasing the psychological proximity that farmers feel with them and encouraging greater uptake of veterinary advice by paying attention to the broader aspects of psychological proximity than only trust, such as taking up a farmer perspective on disease control.

In contrast to the relationship with veterinarians, trust in farmers was more important than psychological proximity for BVD control, with a lack of trust in farmers associated with farmers either maintaining a closed herd separated from neighboring stock or using many methods of control if they had an open herd. Farmers often ensure that they buy animals from other farmers that they trust (Hernández-Jover et al., 2016), and maintaining a closed, separate herd offers even more protection against disease that may be transmitted from farmers that are not trusted. Lack of trust in other farmers has previously been reported as a barrier to biosecurity uptake, with farmers unwilling to contribute to collective action that they do not trust other farmers to engage in (Heffernan et al., 2008; Shortall et al., 2016). This leads them to support greater regulation by government to ensure that all farmers play their part in controlling disease (Heffernan et al., 2016). This opinion was also voiced by some of the farmers in the focus groups in this study in the context of national BVD eradication. In contrast, farmers who were prepared to invest everything in another unknown farmer in the economic games with a high expectation that the other farmer will be fair in return, the "mutually beneficial joint maximizers" class, were more likely to take care introducing new stock and test their cattle, than do nothing. High investment in the investment game indicates both a high level of trust in the other farmer and a willingness to take risks (Chetty et al., 2021). Maximizing the growth of the investment also leads to the greatest resource to the farming community, regardless of whether the other farmer returns any of the investment to the donor farmer. These communityminded, trusting farmers were more likely to rely on testing and the status of the herds that they buy from rather than be in the most self-protective behavior classes. Testing and checking herd status are both behaviors associated with BVD accreditation schemes, so these farmers may have bought into the importance of BVD control for the whole farming community. Most of the farmers surveyed invested less than the $50 \%$ that is typical in other research (Johnson and Mislin, 2011); therefore, although lack of trust in farmers is positive in terms of farmers taking responsibility for protecting their own herd from BVD, the tendency of farmers to think only of their own herd has implications for being able to achieve national disease control via voluntary and cohesive farmer action.

In terms of general other-regarding preferences, $75.4 \%$ of farmers were categorized as prosocial, with almost everyone else classed as individualistic. This distribution of SVO categories was similar to other studies but with a higher proportion of prosocials than the typical 65\% (Murphy and Ackermann, 2014). Prosocials can be further divided into those who wish to minimize inequality between themselves and someone else and those who wish to maximize joint gain. Differentiating between these groups requires additional SVO slider measure questions (Murphy et al., 2011), which were not included in the survey to maintain brevity and achieve a good response rate. Further research into how prosocial UK farmers subdivide and any associations with infectious disease control behavior would be worthwhile. When exploring broader other-regarding preferences (i.e., altruism, prosociality, and trust) in the dictator and trust games we identified 4 classes of other-regarding preferences for farmers. Therefore, farmers are heterogeneous in terms of the other-regarding strategies and these differences need to be accounted for to understand how farmers' other-regarding preferences influence behavior.

Farmers with high motivation to control infectious diseases were more likely to use vaccination, especially with other preventive measures. Both reflective (goals and decision making) and automatic (habits and emotions) motivation were associated with vaccine use, with a slightly higher effect from reflective motivation. Aspects of reflective motivation have been well researched in infectious disease control and farmers are more likely to control disease in their herd if they take responsibility for disease control, want to see the benefits of controlling infectious diseases, or have goals to reduce or remove disease from their herd (Ellis-Iversen et al., 2010; Azbel-Jackson et al., 2018; Robinson, 2020). The emotional aspects of automatic motivation are known to affect farmer behavior (O'Kane et al., 2017). Infectious disease is frequently an emotive subject for farmers and worry often leads farmers to take preventive action to prevent the negative consequences of disease (Suit-B et al., 2020; Doidge et al., 2021). Habit could also be a factor and habitually getting vaccinated is important in human vaccination behavior (Pot et al., 2017). Habit is often a barrier to changing farmer behavior (Coyne et al., 2020) and some farmers in the focus groups viewed the BVD vaccine as insurance. Vaccination could therefore be being used both habitually once a farmer starts 
vaccinating and as a protection against the worry of a BVD outbreak. Both motivation factors were correlated with the "controlling disease for self and other" factor, which is unsurprising because motivation is closely associated with behavior in the COM-B framework and farmers who were proactively controlling disease would have scored highly in the "controlling disease for self and other" factor (Michie et al., 2011).

Farmers who felt that they understood how and why they should control infectious disease (psychological capability) and had the time and money to do so (physical opportunity) were more likely to keep a closed herd, separated from neighboring stock, and undertake BVD testing. Although maintaining a closed, separate herd is very effective at preventing many infectious diseases, it is not very practical for farmers (Shortall et al., 2017). Psychological capability and physical opportunity were correlated with each other and with automatic and reflective motivation and form the context for farmer behavior; therefore, they all need to be taken into account when considering behavior change (Michie et al., 2011). Psychological capability had a greater effect on behavior than physical opportunity, suggesting that knowledge and understanding of how and why to prevent disease is more important for maintaining a closed and separate herd than time or money, perhaps because farmers often appreciate the economic benefits of preventing and controlling disease in their cattle (Oliveira et al., 2018; Robinson, 2020). There has been substantial research into how to encourage farmers to uptake disease control behavior and this finding highlights the importance of effective knowledge transfer to farmers, but this needs to be in combination with ensuring that farmers have the physical resources to carry out the behavior.

Our findings are likely to be generalizable to other similar endemic diseases and farmers in other countries with similar experiences of veterinarians, government, and neighbors; however, further study will be needed to investigate this. The farmers in the study were biased toward English farmers (73\% were English compared with $48 \%$ in the national population; Agriculture and Horticulture Development Board, 2019), therefore, the psychosocial profiles of the general cattle farmer population may be slightly different. However, country was not a confounder in the multinomial model. Respondents may also have been more interested in infectious diseases than the general farming population; however, $12 \%$ of farmers were still doing very little if anything to control BVD and differences were found in both farmer attitudes and BVD control practices.

From these findings, we recommend that trust and proximity to veterinarians and farmers may be crucial to enhancing infection control. One way to achieve this may be to capitalize on conditional cooperation effects (Fischbacher et al., 2001). Conditional cooperation occurs when people are aware that others are also cooperating, and this increases the probability that they will cooperate (Rustagi et al., 2010). This requires making others' cooperation behavior observable (Bradley et al., 2018) and has been effectively implemented using social media (Cameron et al., 2013).

In conclusion, psychosocial factors are important for UK cattle farmer uptake of BVD control. Psychological proximity to veterinarians was a novel factor associated with proactive BVD control and was more important here than the more extensively investigated trust. In addition, lack of trust in other farmers, a high understanding of how and why to control infectious disease, time and money, and both automatic and reflective motivation were also associated with farmers' approach to BVD control. These findings highlight the importance of a close veterinarian-farmer relationship and are important for promoting effective BVD control by farmers, which has implications for successful nationwide BVD control and eradication schemes.

\section{ACKNOWLEDGMENTS}

All authors acknowledge the Biotechnology and Biological Sciences Research Council (Swindon, Wiltshire, UK, grant numbers BB/5016341/1 and BB/ $\mathrm{S} 01750 \mathrm{X} / 1)$ for funding this project. The funders had no other role in the data collection, analysis, or decision to publish. The authors also thank the participating farmers in the focus groups and the survey, the Agriculture and Horticulture Development Board (Kenilworth, Warwickshire, UK), especially Derek Armstrong and Jenny Gibbons, for collaborating on and disseminating the survey, and all the groups and organizations that promoted the survey. The authors have not stated any conflicts of interest.

\section{REFERENCES}

Abernethy, D. A., J. Moscard-Costello, E. Dickson, R. Harwood, K. Burns, E. McKillop, S. McDowell, and D. U. Pfeiffer. 2011. Epidemiology and management of a bovine brucellosis cluster in Northern Ireland. Prev. Vet. Med. 98:223-229. https://doi.org/10.1016/ j.prevetmed.2010.11.002.

Agriculture and Horticulture Development Board. 2019. The UK Cattle Yearbook 2019. Agriculture and Horticulture Development Board.

Aron, A., E. N. Aron, and D. Smollan. 1992. Inclusion of other in the self scale and the structure of interpersonal closeness. J. Pers. Soc. Psychol. 63:596-612. https://doi.org/10.1037/0022-3514.63.4.596.

Azbel-Jackson, L., C. Heffernan, G. Gunn, and J. Brownlie. 2018. Exploring the role of voluntary disease schemes on UK farmer bio-security behaviours: Findings from the Norfolk-Suffolk Bovine Viral Diarrhoea control scheme. PLoS One 13:e0179877. https:// doi.org/10.1371/journal.pone.0179877. 
Bard, A. M., D. Main, E. Roe, A. Haase, H. R. Whay, and K. K. Reyher. 2019. To change or not to change? Veterinarian and farmer perceptions of relational factors influencing the enactment of veterinary advice on dairy farms in the United Kingdom. J. Dairy Sci. 102:10379-10394. https://doi.org/10.3168/jds.2019-16364.

Barker, F., L. Atkins, and S. de Lusignan. 2016. Applying the COM-B behaviour model and behaviour change wheel to develop an intervention to improve hearing-aid use in adult auditory rehabilitation. Int. J. Audiol. 55(suppl 3):S90-S98. https://doi.org/10.3109/ 14992027.2015.1120894.

Bauch, C. T., and D. J. D. Earn. 2004. Vaccination and the theory of games. Proc. Natl. Acad. Sci. USA 101:13391-13394. https://doi .org/10.1073/pnas.0403823101.

Berg, J., J. Dickhaut, and K. McCabe. 1995. Trust, reciprocity, and social-history. Games Econ. Behav. 10:122-142. https://doi.org/10 $.1006 /$ game.1995.1027.

Bobak, A., and T. Raupach. 2018. Effect of a short smoking cessation training session on smoking cessation behavior and its determinants among general practitioner trainees in England. Nicotine Tob. Res. 20:1525-1528. https://doi.org/10.1093/ntr/ntx241.

Böhm, R., C. Betsch, and L. Korn. 2016. Selfish-rational non-vaccination: Experimental evidence from an interactive vaccination game. J. Econ. Behav. Organ. 131:183-195. https://doi.org/10.1016/j .jebo.2015.11.008.

Bradley, A., C. Lawrence, and E. Ferguson. 2018. Does observability affect prosociality? Proc. Biol. Sci. 285:20180116. https://doi.org/ 10.1098/rspb.2018.0116.

Braun, V., and V. Clarke. 2006. Using thematic analysis in psychology. Qual. Res. Psychol. 3:77-101. https://doi.org/10.1191/ 1478088706qp063oa.

Brennan, M. L., and R. M. Christley. 2013. Cattle producers' perceptions of biosecurity. BMC Vet. Res. 9:71. https://doi.org/10.1186/ 1746-6148-9-71.

Bshary, R., and R. Bergmüller. 2008. Distinguishing four fundamental approaches to the evolution of helping. J. Evol. Biol. 21:405-420. https://doi.org/10.1111/j.1420-9101.2007.01482.x.

BVDFree. 2021. BVDFree. Accessed Aug. 6, 2021. https://bvdfree.org $. u \mathrm{k} /$.

Cameron, A. M., A. B. Massie, C. E. Alexander, B. Stewart, R. A. Montgomery, N. R. Benavides, G. D. Fleming, and D. L. Segev. 2013. Social media and organ donor registration: The Facebook effect. Am. J. Transplant. 13:2059-2065. https://doi.org/10.1111/ ajt.12312.

Carroll, G. A., and J. M. Groarke. 2019. The importance of the social sciences in reducing tail biting prevalence in pigs. Animals (Basel) 9:591. https://doi.org/10.3390/ani9090591.

Charness, G., U. Gneezy, and B. Halladay. 2016. Experimental methods: Pay one or pay all. J. Econ. Behav. Organ. 131:141-150. https: //doi.org/10.1016/j.jebo.2016.08.010.

Chetty, R., A. Hofmeyr, H. Kincaid, and B. Monroe. 2021. The trust game does not (only) measure trust: The risk-trust confound revisited. J. Behav. Exp. Econ. 90:101520. https://doi.org/10.1016/ j.socec.2020.101520.

Cialdini, R. B., S. L. Brown, B. P. Lewis, C. Luce, and S. L. Neuberg. 1997. Reinterpreting the empathy-altruism relationship: When one into one equals oneness. J. Pers. Soc. Psychol. 73:481-494. https:/ /doi.org/10.1037/0022-3514.73.3.481

Coyne, L. A., C. Bellet, S. M. Latham, and D. Williams. 2020. Providing information about triclabendazole resistance status influences farmers to change liver fluke control practices. Vet. Rec. 187:357. https://doi.org/10.1136/vr.105890.

Dimick, M., D. Rueda, and D. Stegmueller. 2018. Models of otherregarding preferences, inequality, and redistribution. Annu. Rev. Polit. Sci. 21:441-460. https://doi.org/10.1146/annurev-polisci -091515-030034.

Doidge, C., E. Ferguson, F. Lovatt, and J. Kaler. 2021. Understanding farmers' naturalistic decision making around prophylactic antibiotic use in lambs using a grounded theory and natural language processing approach. Prev. Vet. Med. 186:105226. https://doi.org/ 10.1016/j.prevetmed.2020.105226.
Ellis-Iversen, J., A. J. C. Cook, E. Watson, M. Nielen, L. Larkin, M. Wooldridge, and H. Hogeveen. 2010. Perceptions, circumstances and motivators that influence implementation of zoonotic control programs on cattle farms. Prev. Vet. Med. 93:276-285. https://doi .org/10.1016/j.prevetmed.2009.11.005.

Engel, C. 2011. Dictator games: A meta study. Exp. Econ. 14:583-610. https://doi.org/10.1007/s10683-011-9283-7.

Fagerland, M. W., and D. W. Hosmer. 2012. A generalized Hosmer-Lemeshow goodness-of-fit test for multinomial logistic regression models. Stata J. 12:447-453. https://doi.org/10.1177/ $1536867 X 1201200307$.

Fehr, E., and U. Fischbacher. 2003. The nature of human altruism. Nature 425:785-791. https://doi.org/10.1038/nature02043.

Ferguson, E. 2022. What blood and organ donation can tell us about cooperation? Curr. Opin. Psychol. 44:202-207. https://doi.org/10 .1016/j.copsyc.2021.09.005.

Ferguson, E., F. Atsma, W. de Kort, and I. Veldhuizen. 2012. Exploring the pattern of blood donor beliefs in first-time, novice, and experienced donors: Differentiating reluctant altruism, pure altruism, impure altruism, and warm glow. Transfusion 52:343-355. https://doi.org/10.1111/j.1537-2995.2011.03279.x.

Ferguson, E., K. Zhao, and L. D. Smillie. 2020. Personality, preferences and socioeconomic behavior. Pages 477-493 in Cambridge Handbook of Personality Psychology, 2nd ed. P. J. Corr and G. Matthews, ed. Cambridge University Press.

Fischbacher, U., S. Gachter, and E. Fehr. 2001. Are people conditionally cooperative? Evidence from a public goods experiment. Econ. Lett. 71:397-404. https://doi.org/10.1016/S0165-1765(01)00394-9.

Fisher, R. 2013. 'A gentleman's handshake': The role of social capita and trust in transforming information into usable knowledge. J. Rural Stud. 31:13-22. https://doi.org/10.1016/j.jrurstud.2013.02 .006 .

Forsythe, R., J. L. Horowitz, N. E. Savin, and M. Sefton. 1994. Fairness in simple bargaining experiments. Games Econ. Behav. 6:347369. https://doi.org/10.1006/game.1994.1021.

Fraley, C., and A. E. Raftery. 2002. Model-based clustering, discriminant analysis, and density estimation. J. Am. Stat. Assoc. 97:611631. https://doi.org/10.1198/016214502760047131.

Graham, D. A., T. A. Clegg, H. H. Thulke, P. O'Sullivan, G. McGrath, and S. J. More. 2016. Quantifying the risk of spread of bovine viral diarrhoea virus (BVDV) between contiguous herds in Ireland. Prev. Vet. Med. 126:30-38. https://doi.org/10.1016/j.prevetmed 2016.01.017.

Gunn, G. J., H. W. Saatkamp, R. W. Humphry, and A. W. Stott. 2005. Assessing economic and social pressure for the control of bovine viral diarrhoea virus. Prev. Vet. Med. 72:149-162. https:// doi.org/10.1016/j.prevetmed.2005.08.012.

Gwaredu BVD. 2019. Animal Health \& Welfare Wales. Accessed Aug. 6, 2021. https://www.ahww.cymru/en/.

Hardefeldt, L. Y., J. R. Gilkerson, H. Billman-Jacobe, M. A. Stevenson, K. Thursky, K. E. Bailey, and G. F. Browning. 2018. Barriers to and enablers of implementing antimicrobial stewardship programs in veterinary practices. J. Vet. Intern. Med. 32:1092-1099. https://doi.org/10.1111/jvim.15083.

Heffernan, C., L. Azbel-Jackson, J. Brownlie, and G. Gunn. 2016. Farmer attitudes and livestock disease: exploring citizenship behaviour and peer monitoring across two BVD control schemes in the UK. PLoS One 11:e152295. https://doi.org/10.1371/journal .pone.0152295.

Heffernan, C., L. Nielsen, K. Thomson, and G. Gunn. 2008. An exploration of the drivers to bio-security collective action among a sample of UK cattle and sheep farmers. Prev. Vet. Med. 87:358-372. https://doi.org/10.1016/j.prevetmed.2008.05.007.

Hernández-Jover, M., V. Higgins, M. Bryant, L. Rast, and C. McShane. 2016. Biosecurity and the management of emergency animal disease among commercial beef producers in New South Wales and Queensland (Australia). Prev. Vet. Med. 134:92-102. https:// doi.org/10.1016/j.prevetmed.2016.10.005.

Houe, H. 1999. Epidemiological features and economical importance of bovine virus diarrhoea virus (BVDV) infections. Vet. Microbiol. 64:89-107. https://doi.org/10.1016/S0378-1135(98)00262-4. 
Hu, L. T., and P. M. Bentler. 1999. Cutoff criteria for fit indexes in covariance structure analysis: Conventional criteria versus new alternatives. Struct. Equ. Modeling 6:1-55. https://doi.org/10.1080/ 10705519909540118.

Johnson, N. D., and A. A. Mislin. 2011. Trust games: A meta-analysis. J. Econ. Psychol. 32:865-889. https://doi.org/10.1016/j.joep.2011 .05 .007 .

Kleinert, T., B. Schiller, U. Fischbacher, L. A. Grigutsch, N. Koranyi, K. Rothermund, and M. Heinrichs. 2020. The Trust Game for Couples (TGC): A new standardized paradigm to assess trust in romantic relationships. PLoS One 15:e0230776. https://doi.org/10 .1371/journal.pone.0230776.

Kong, D. T. 2018. Trust toward a group of strangers as a function of stereotype-based social identification. Pers. Individ. Dif. 120:265270. https://doi.org/10.1016/j.paid.2017.03.031.

Lee, D. 2013. CARBayes: an R package for Bayesian spatial modeling with conditional autoregressive priors. J. Stat. Softw. 55:1-24. https://doi.org/10.18637/jss.v055.i13.

Mashek, D., L. W. Cannaday, and J. P. Tangney. 2007. Inclusion of community in self scale: A single-item pictorial measure of community connectedness. J. Community Psychol. 35:257-275. https:/ /doi.org/10.1002/jcop.20146.

McClurkin, A. W., E. T. Littledike, R. C. Cutlip, G. H. Frank, M. F. Coria, and S. R. Bolin. 1984. Production of cattle immunotolerant to bovine viral diarrhea virus. Can. J. Comp. Med. 48:156-161.

McKnight, D. H., and N. L. Chervany. 2001. Trust and Distrust Definitions: One bite at a time. Pages 27-54 in Trust in Cyber-Societies: Integrating the Human and Artificial Perspectives. R. Falcone, M. Singh, and Y.-H. Tan, ed. Springer.

Michie, S., L. Atkins, and R. West. 2014. The Behaviour Change Wheel: A guide to designing interventions. Silverback Publishing.

Michie, S., M. M. van Stralen, and R. West. 2011. The behaviour change wheel: A new method for characterising and designing behaviour change interventions. Implement. Sci. 6:42. https://doi .org/10.1186/1748-5908-6-42.

Murphy, R. O., and K. A. Ackermann. 2014. Social value orientation: Theoretical and measurement issues in the study of social preferences. Pers. Soc. Psychol. Rev. 18:13-41. https://doi.org/10.1177/ 1088868313501745.

Murphy, R. O., K. A. Ackermann, and M. J. J. Handgraaf. 2011. Measuring social value orientation. Judgm. Decis. Mak. 6:771-781.

Nowak, M. A. 2006. Five rules for the evolution of cooperation. Science 314:1560-1563. https://doi.org/10.1126/science.1133755.

O'Kane, H., E. Ferguson, J. Kaler, and L. Green. 2017. Associations between sheep farmer attitudes, beliefs, emotions and personality, and their barriers to uptake of best practice: The example of footrot. Prev. Vet. Med. 139:123-133. https://doi.org/10.1016/ j.prevetmed.2016.05.009.

Oliveira, V. H. S., I. Anneberg, H. Voss, J. T. Sorensen, and P. T. Thomsen. 2018. Attitudes of Danish dairy farmers towards biosecurity. Livest. Sci. 214:153-160. https://doi.org/10.1016/j.livsci 2018.06.004.

Peterhans, E., T. W. Jungi, and M. Schweizer. 2003. BVDV and innate immunity. Biologicals 31:107-112. https://doi.org/10.1016/ S1045-1056(03)00024-1.

Pfattheicher, S., Y. A. Nielsen, and I. Thielmann. 2022. Prosocial behavior and altruism: A review of concepts and definitions. Curr. Opin. Psychol. 44:124-129. https://doi.org/10.1016/j.copsyc.2021 .08 .021 .

Pletzer, J. L., D. Balliet, J. Joireman, D. M. Kuhlman, S. C. Voelpel, and P. A. M. Van Lange. 2018. Social value orientation, expectations, and cooperation in social dilemmas: A meta-analysis. Eur. J. Pers. 32:62-83. https://doi.org/10.1002/per.2139.

Pot, M., H. M. van Keulen, R. A. C. Ruiter, I. Eekhout, L. Mollema, and T. Paulussen. 2017. Motivational and contextual determinants of HPV-vaccination uptake: A longitudinal study among mothers of girls invited for the HPV-vaccination. Prev. Med. 100:41-49. https://doi.org/10.1016/j.ypmed.2017.04.005.
R Core Team. 2019. R: A language and environment for statistical computing. R Foundation for Statistical Computing.

Rand, D. G., and M. A. Nowak. 2013. Human cooperation. Trends Cogn. Sci. 17:413-425. https://doi.org/10.1016/j.tics.2013.06.003.

Revelle, W. 2020. psych: Procedures for Personality and Psychological Research. 2.0.8 ed. Northwestern University.

Robinson, P. A. 2020. "They've got to be testing and doing something about it": Farmer and veterinarian views on drivers for Johne's disease control in dairy herds in England. Prev. Vet. Med. 182:105094. https://doi.org/10.1016/j.prevetmed.2020.105094.

Rustagi, D., S. Engel, and M. Kosfeld. 2010. Conditional cooperation and costly monitoring explain success in forest commons management. Science 330:961-965. https://doi.org/10.1126/science .1193649 .

Scrucca, L., M. Fop, T. B. Murphy, and A. E. Raftery. 2016. mclust 5: Clustering, classification and density estimation using Gaussian finite mixture models. R J. 8:289-317. https://doi.org/10.32614/ RJ-2016-021.

Shortall, O., M. Green, M. Brennan, W. Wapenaar, and J. Kaler. 2017. Exploring expert opinion on the practicality and effectiveness of biosecurity measures on dairy farms in the United Kingdom using choice modeling. J. Dairy Sci. 100:2225-2239. https:// doi.org/10.3168/jds.2016-11435.

Shortall, O., A. Ruston, M. Green, M. Brennan, W. Wapenaar, and J. Kaler. 2016. Broken biosecurity? Veterinarians' framing of biosecurity on dairy farms in England. Prev. Vet. Med. 132:20-31. https: //doi.org/10.1016/j.prevetmed.2016.06.001.

Suit-B, Y., L. Hassan, S. E. Krauss, S. Z. Ramanoon, P. T. Ooi, A. Yasmin, and J. Epstein. 2020. Exploring the mental model of cattle farmers in disease prevention and control practices. Vet. Sci. 7:27. https://doi.org/10.3390/vetsci7010027.

Taylor, M. J., D. Arriscado, I. Vlaev, D. Taylor, P. Gately, and A. Darzi. 2016. Measuring perceived exercise capability and investigating its relationship with childhood obesity: A feasibility study. Int. J. Obes. (Lond.) 40:34-38. https://doi.org/10.1038/ijo.2015.210.

Thurstone, L. L. 1947. Multiple-factor analysis: A development and expansion of the vectors of the mind. The University of Chicago Press.

Tu, K. C., S. Chen, and R. M. Mesler. 2021. Trait self-construal, inclusion of others in the self and self-control predict stay-at-home adherence during COVID-19. Pers. Individ. Dif. 175:110687. https: //doi.org/10.1016/j.paid.2021.110687.

Venables, W. N., and B. D. Ripley. 2002. Modern Applied Statistics with S. 4th ed. Springer.

Vernon, M. C. 2011. Demographics of cattle movements in the United Kingdom. BMC Vet. Res. 7:31. https://doi.org/10.1186/1746-6148 $-7-31$.

Weldegebriel, H. T., G. J. Gunn, and A. W. Stott. 2009. Evaluation of producer and consumer benefits resulting from eradication of bovine viral diarrhoea (BVD) in Scotland, United Kingdom. Prev. Vet. Med. 88:49-56. https://doi.org/10.1016/j.prevetmed.2008.07 .001 .

West, S. A., A. S. Griffin, and A. Gardner. 2007. Social semantics: Altruism, cooperation, mutualism, strong reciprocity and group selection. J. Evol. Biol. 20:415-432. https://doi.org/10.1111/j.1420 $-9101.2006 .01258 . x$

\section{ORCIDS}

N. S. Prosser (® https://orcid.org/0000-0001-8391-7153

M. J. Green (ํ) https://orcid.org/0000-0002-6408-6443

E. Ferguson (๑) https://orcid.org/0000-0002-7678-1451

M. J. Tildesley (®) https://orcid.org/0000-0002-6875-7232

E. M. Hill ๑ https://orcid.org/0000-0002-2992-2004

M. J. Keeling (ㄴ) https://orcid.org/0000-0003-4639-4765

J. Kaler ( $)$ https://orcid.org/0000-0002-3332-7064 